\title{
Evaluation of the Efficacy of a Field Isolate of Eimeria Oocysts Immunization in Two Breeds of Chickens - Demystifying use of Coccidiosis Vaccines
}

\author{
Lucas Atehmengo Ngongeh ${ }^{1}$, Felix Ezuchukwu Nwaiwu ${ }^{1}$, Barineme Beke Fakae,"* \\ ${ }^{1}$ Department of Veterinary Parasitology and Entomology, College of Veterinary Medicine, Michael Okpara University of Agriculture, \\ Umudike, Nigeria \\ ${ }^{2}$ Department of Applied and Environmental Biology, Rivers State University of Science and Technology \\ Port Harcourt, Nigeria \\ ${ }^{*}$ Corresponding author's email: bbfakae [AT] ust.edu.ng
}

\begin{abstract}
Immunization efficacy of a field isolate of unattenuated sporulated Eimeria oocysts in broiler and Nigerian indigenous chickens (NIC) was investigated. Both breeds of birds were grouped and inoculated with varying dose levels (750, 1500 and 3000) of the oocysts per bird. The immunizing infections were truncated with an anticoccidial drug following detection of patency evident by presence of Eimeria oocysts in the faeces of inoculated birds on day 4 of inoculation. Immunized birds were then given challenged infections of 10,000 oocysts of the same Eimeria isolate per bird and an additional group that did not receive the immunizing infections was also challenged with 10,000 oocysts to serve as the unimmunized-challenged control while another group remained as uninfectedunchallenged control. Immunized birds were found to be protected against the challenge infections evident by having significantly less severe gross lesion scores ( $(0$ to 1$)$ in contrast to the unimmunized-challenged control birds (which had lesion scores of 2 to 4 and 1 to 2 in broiler and indigenous chickens respectively). The infection was more severe in broiler chickens in contrast to the indigenous chickens judged by more severe lesion scores and significantly higher oocysts counts in the broilers. Broilers also had significantly lower PCV $(P<0.05)$ in comparison to their indigenous counterparts. Infected birds generally suffered infections more in contrast to the uninfected control birds judged by the significantly higher body weights and PCV of the uninfected birds $(P<0.05)$. The results showed that the protection of birds against coccidiosis by immunization with the Eimeria isolate is feasible and this can therefore serve as a premise for the recommendation of immunization against coccidioisis in eastern Nigeria where the practice is extremely low or unknown by poultry farmers and hardly recommended to poultry producers by veterinarians and their allies in spite of the endemicty and severity of the disease in the area. All the dose levels tried in this study were protective with no obvious differences between the dose levels and we recommended the use of 750 oocysts of such isolates to minimize the risk clinical coccidiosis. Local isolates of Eimeria would also have the added advantage in that they are likely to contain multiple Eimeria species that could provide full protection against the entire spectrum of Eimeria that occur in the area.
\end{abstract}

\section{INTRODUCTION}

The poultry industry is very crucial given the numerous roles it plays such as source of animal protein for human nutrition, job creation and economic earnings to name but a few. However, birds are susceptible to a lot of diseases amongst which is coccidiosis [1]. Coccidiosis is caused by Emeria species and ravages poultry worldwide [2]. Economic losses due to coccidiosis have been estimated at 3 billion dollars worldwide yearly [3]. The losses are usually due to poor weight gain, reduced weight gain, weight loss, reduced egg production, mortalities and cost of control processes.

In order to curb production losses due to coccidiosis, anticoccidial drugs are largely being used, however, the increasing demand for organic products by consumers and increase rate of drug resistance against Eimeria species have decreased the popularity and effectiveness of control by use of the drugs $[4,5]$ thereby posing a threat to the continuous development of the industry. This necessitates the development of novel methods for the control of coccidiosis and so far vaccines are increasingly the most desirable option. The most commonly used coccidiosis vaccines are the live vaccines, which stimulate protective immunity due to the first small dose of the vaccinal oocysts and enhanced through the cycling of the parasites through the faecal-oral route $[6,7]$. 
Immunity to avian cocccidia is species-specific [8,9] and this is crucial in that chickens infected with Eimeria will develop immunity against the Eimeria species involved in the infection but not to other Eimeria species. The significance of this is that there is no cross protection against other species of Eimeria that are not a component of such a vaccine. However, most experimental studies on the topic usually adopt/use only one or very few types of Eimeria species. In the same way, E. acervulina, E. maxima and E. tenella are said to be the only Eimeria species included in most commercially available vaccines [10]. Worse even is CocciVac $®$ which is the first commercial live vaccine produced in 1952 together with its modified forms namely, Coccivac B, Coccivac D and Immucox which comprised of E. tenella oocysts only and are still currently in use in 40 countries [11, 12]. The study of Ngongeh [13] revealed four different species of Eimeria namely E. acervulina, E. necatrix, E. praecox and E. tenella infecting chickens reared in Nsukka area in Enugu state in eastern Nigeria. A good vaccine for use in such a locality should therefore contain all the four species for full spectrum of protection.

Among the factors that influence the induction of solid immunity is the dose level of primary/immunizing infection, meanwhile the severity of infection and disease in chickens under field conditions is said to be related to age and breed of chicken, previous exposure, and the degree of exposure to the sporulated oocysts [14]. For example, different lines of chickens (Mandarah and Fayoumi lines from Egypt, Rhode Island Red line, and two White Leghorn lines) were shown to have large differences in resistance to E. tenella with the Fayoumi line and the WLDW being the most resistant and most susceptible lines respectively [15].

Vaccination of poultry against coccidiosis is not yet a common or routine practice in the eastern region of Nigeria where this study was performed partly due to unawareness of both poultry farmers and veterinarians and other allied professionals and/or high level of scepticism among the few who know about control of coccidiosis by vaccination in principle and neither do commercial hatcheries in Nigeria adopt the practice at hatchery level. More so, vaccines known to be effective against some Eimeria species may not be effective against others or even similar Eimeria species from other regions/environments, i.e. different strains. Again different breeds of chickens may respond differently to coccidiosis and other parasitic diseases.

Finding genes associated with coccidiosis resistance will be useful for efficient genetic selection for disease resistant lines and understanding mechanisms underlining disease in chickens [16]. Fortunately, there is evidence that resistance and susceptibility to avian cocccidiosis are associated with inheritance [17], thus chicken lines resistant to avian coccidiosis could be established by genetic selection [18]. For sustainable control of coccidiosis, the Eimeria-host interactions should be explored at both species and strain levels and isolates of important parasites in various environments may need to be studied. Data emanating from such studies would inform the decision as to what Eimeria species or strains to be included in vaccines for the control of coccidiosis in such environments for good results rather than just administering any available coccidiosis vaccine that may be useful only in some specific localities.

Vaccines to be used in an environment should contain the full spectrum of the important pathogenic Eimeria species in that environment given the response is specific in nature, and it is for this reason that it is recommended to consider all the seven ubiquitous Eimeria species when preparing a vaccine [19, 20, 21].

There is no documented research or evidence about the response of the Nigerian indigenous chicken to coccidiosis vaccines and experimental Eimeria infections in general in comparison to their exotic counterparts such as the broiler and layer chickens. It is worthy of note that in broilers, application of coccidiosis vaccines has been slow to gain acceptance due to economic reasons, perceived adverse effects on early chick growth particularly with nonattenuated vaccines, and concerns about timely onset of protective immunity because they are very short-lived birds [12].

Immunizing infections using graded doses of a local isolate of field strain of Eimeria oocysts in both broiler and indigenous chickens would give an insight on the practicality/efficacy of coccidiosis vaccines. If the Eimeria isolate is found to be protective then field/commercial trials of coccidiosis vaccines for the control of coccidiosis will be encouraged in Umuahia area and the entire eastern region of Nigeria in general thereby demystifying the use of coccidiosis vaccines, if the trials are successful. A difference in response of the two breeds might also exist and once that is established, the genes of the more resistant breed could be exploited for the control of coccidiosis. The field caecal isolate of Eimeria used in the study is likely to contain multiple species of Eimeria that occur in the area thereby representing a good field situation in the area.

This study was therefore conducted to investigate (i) the immunization efficacy of a field caecal isolate of Eimeria oocysts from chickens reared in the Umuahia area in eastern Nigeria in 3 weeks old broiler and Nigerian indigenous chickens, (ii) the influence of dose level of the immunizing/primary infection in the immunization process and (iii) if there is a difference in response of the two breeds, broiler and local chickens.

The study is significant in that if the Eimeria isolate is found to be protective against coccidiosis, then it can be the premise for a preliminary step to convince poultry farmers in the region to vaccinate against poultry coccidiosis. An added advantage would be that such a crude isolate ('vaccine') could be used during scarcity of standard commercial vaccines for vaccination of birds hence its sustainability. Another advantage is that if such 'vaccines' are used in their 
immediate environment from where they were isolated, they would have the potential to provide a full spectrum of protection since it will likely contain all the important Eimeria species in that area.

\section{MATERIALS AND METHODS}

\section{Study Area}

The experiment was carried out in the poultry house of the College of Veterinary Medicine in Michael Okpara University of Agriculture, Umudike (MOUAU) Farm. The laboratory procedures were carried out in the Veterinary Parasitology laboratory in MOUAU.

\section{Experimental Birds}

The study was carried out at the Poultry unit of the Teaching and Research Farm, College of Veterinary Medicine, MOUAU. Broiler chicks of Anak 2000 breed (commonly reared in Nigeria due to their big size and body conformation and white colour) were procured while Nigerian indigenous (Normal feathered local chicken) chicks were obtained from local chicken breeders hatched from a parent stock from the Department of Animal Science, University of Nigeria, Nsukka where they are maintained. The birds were acquired at day old and brooded. All the birds were managed in deep litter system in the course of the experiment (after their first week of life on newspapers on the floor) and the litter was maintained dry by avoiding water spillage and by replacing litter with fresh dry wood shavings every two days. The birds were duly vaccinated against viral infections (Newcastle disease and infectious bursal disease). Prophylactic treatment against Eimeria infections in the course of brooding was done with toltrazuril (Baycox $2.5 \%$ w/v Oral Solution) which was withdrawn before experimental infections. The birds were fed ad libitum throughout the brooding and experimental periods.

All relevant laws and codes of practice governing the experimental studies with life animals were complied as stipulated by Ward and Elsea [22], (and the experimental protocol was approved by MOUAU Animal Ethics Committee. Broiler starter marsh $\left(\right.$ Top Feed ${ }^{\circledR}$ ) and water were provided ad libitum throughout the experiment to both breeds of birds.

\section{Eimeria Isolate}

The Eimeria used for the study was isolated from the caeca of 3 to 4 weeks old broiler chickens clinically sick of coccidiosis as described by Ngogeh et al. (2017) but with slight modifications. The caeca were collected during post mortem and incised and the contents which were largely blood and caecal cores were washed into sieves placed in small bowls and caecal cores crushed with a spatula. Caeca with much faecal material were avoided in order to obtain a clear Eimeria oocyst suspension for easy quantification and dose determination. The filtrate was poured in 400ml beakers and washed thrice with water in order to remove the red colour of blood by allowing the suspension to sediment for 10 minutes before decanting each time. Following washing, the sediment was examined to confirm the presence of the oocysts. The sediment was resuspended in $100 \mathrm{ml}$ of water and $20 \mathrm{ml}$ of the Eimeria suspension was dispensed into each Petri dish. $1 \mathrm{ml}$ of the sporulating agent, $2.5 \%$ potassium dichromate $\left(\mathrm{KCrO}_{4}\right)$, was then added into each Petri dish and incubated at room temperature $\left(27-28^{\circ} \mathrm{c}\right)$ on bench tops in the Parasitology Laboratory in MOUAU for five days.

Following sporulation, the suspensions were recollected in a $400 \mathrm{ml}$ beaker and more water was poured into the suspension, allowed to sediment for 20 minutes and then decanted in order to wash out the $\mathrm{KCrO}_{4}$. The suspension was allowed to sediment for 20 minutes before decanting each time and this was repeated twice. The caecal Eimeria isolate was then put into a $50 \mathrm{ml}$ Teflon tube and preserved in the refrigerator $\left(4^{\circ} \mathrm{C}\right)$ until it was used for the experimental infections two weeks later.

\section{Experimental Design and Infection}

Forty two broiler and twenty five local chickens (three-week old) were used for the study. The chickens were all screened for the presence of Eimeria oocysts two days before the experimental infections and were found to be free of natural infections. Following brooding, the birds were grouped and placed in separate pens (Table 1). The broiler chickens were randomly distributed into four groups with groups 1, 2 and 3 containing seven birds each while group 4 contained 14 chickens. On the other hand the indigenous (local) chickens were also randomly distributed into four groups with groups 1, 2 and 3 having five birds each while group 4 had 10 chickens (the fewer number of birds per group was due to the scarcity of indigenous chickens at that time). Group 4 of each breed of birds served as uninfected controls. The birds were given primary immunizing infections with graded dose levels of sporulated Eimeria oocysts (Table 1).

Following establishment of patency of the primary immunizing infections on day 4, all birds were treated with an anticoccidial (Toltrazuril ${ }^{\circledR}$ ) from day 4 for two consecutive days to truncate the immunizing Eimeria infections. Following completion of administration of the treatment, the birds were allowed for 4 days for the drug to clear from their systems before the challenge infections were introduced (Table 2). In the challenge infections, groups 1, 2 and 3 remained as in the primary infections for both breeds of birds while groups 4 of the broiler was bifurcated into groups 4 
and 5 containing 7 birds. On the other hand the indigenous chickens were also bifurcated into groups 4 and 5 with each containing 5 birds. Infections were performed as indicated in the design (Table 2). In the new arrangement group 4 of each breed of birds was infected while group 5 remained as uninfected controls (Table 2).

\section{Infection of Chickens with Sporulated Eimeria Oocysts}

Dose levels were determined using standard procedures. Chickens were infected orally with standardised doses of Eimeria oocysts by delivering the oocyst suspension into the mouth of each of the chickens to be infected using a tuberculin syringe which was rinsed with distilled water each time before inoculation of a different bird. The infected birds were monitored for 16 days during which body weight (Bwt), packed cell volume (PCV), clinical signs and faecal oocyst counts (OPG) were determined/assessed/measured.

Table 1. Experimental design: Primary/immunizing infections in chickens with graded dose levels of sporulated Eimeria oocyst.

\begin{tabular}{rlrrrr}
\hline \multicolumn{1}{c}{ Group } & $\begin{array}{c}\text { Numberof } \\
\text { chickens }\end{array}$ & $\begin{array}{c}\text { Dose level of } \\
\text { Eimeria } \text { oocysts }\end{array}$ & $\begin{array}{c}\text { Treatment with } \\
\text { Toltrazuril }\end{array}$ & Day of treatment \\
\hline 1. & Broiler chickens & 7 & 3,000 & Treated & 4 \\
2. & Broiler chickens & 7 & 1,500 & Treated & 4 \\
3. & Broiler chickens & 7 & 750 & Treated & 4 \\
4. & Broiler chickens & 14 & 0 & Treated & 4 \\
1. Local chickens & 5 & 3,000 & Treated & 4 \\
2. Local chickens & 5 & 1,500 & Treated & 4 \\
3. Local chickens & 5 & 750 & Treated & 4 \\
4. Local chickens & 10 & 0 & Treated & 4 \\
\hline
\end{tabular}

Table 2: Experimental design: challenge infection of chickens with sporulated Eimeria oocysts.

\begin{tabular}{llcrc}
\hline \multicolumn{1}{c}{ Group } & $\begin{array}{c}\text { Number } \\
\text { Of chickens }\end{array}$ & $\begin{array}{c}\text { Dose level of Eimeria } \\
\text { oocysts }\end{array}$ & Day of Necropsy \\
\hline 1. & Broiler chickens & 7 & 10,000 & Day 16 \\
2. & Broiler chickens & 7 & 10,000 & Day 16 \\
3. & Broiler chickens & 7 & 10,000 & Day 16 \\
4. & Broiler chickens & 7 & 10,000 & Day 16 \\
5. & Broiler chickens & 7 & 0 & Day 16 \\
1. & Local chickens & 5 & 10,000 & Day 16 \\
2. & Local chickens & 5 & 10,000 & Day 16 \\
3. & Local chickens & 5 & 10,000 & Day 16 \\
4. & Local chickens & 5 & 10,000 & Day 16 \\
5. Local chickens & 4 & 0 & Day 16 \\
\hline
\end{tabular}

\section{Feed Intake}

Feed was weighed using a weighing balance (Camry; China) each day/time before introduction into each feeding trough and weighed again at the end of the day and the difference deduced between the readings was the feed consumed (FC) for the group for that day, and this was done daily throughout the study. The mean feed consumption per was deduced by dividing the total amount of feed consumed by the number of birds in that group.

\section{Body Weight}

The body weight (BWt) of each bird in all the groups was taken every 4 days from day 0 till the end of the experiment on day 16 using a weighing balance (Camry®; China).

\section{Packed Cell Volume}

The Packed cell volume (PCV) of all the experimental animals was taken every 4 days from day 0 to the end of the experiment on day 16. Blood was collected through the jugular vein directly into heparinised capillary tubes (Camlab Ltd., Cambridge) for determination of PCV [23].

\section{Clinical Signs}

The birds were observed closely (morning, afternoon and evening daily beginning from day 2 following infection) through out the experiment for evidence of morbidity such as dullness, diarrhoea, clustering, drooping of wings, anorexia and mortality. 


\section{Faecal Oocyst Counts}

The screening for faecal oocysts were conducted daily from day 3 of infection till patency was established and there after OPG was conducted thrice a week using both flotation and McMaster techniques [24].

\section{Gross Lesions and Lesion Score}

Four birds from each group were humanely euthanized by cervical dislocation at the end of the study (day 16) as described by Zander [25]. Gross lesions such as intestinal haemorrhages, necrotic foci and bloody caecal contents or caecal cores were checked. Coccidial lesion scoring was conducted for the caeca as a means of assessing the severity of the infection and gross lesions were graded from 0 to 4 based on lesion score key [26, 27]. A lesion score of zero represents absence of lesion while a lesion score of four indicates very severe intestinal/caecal mucosa lesion.

\section{Microscopic Lesions}

Intestinal tissues from various sections of the intestine were collected at necropsy for histopathological studies from all sections of the intestine (duodenum, jejunum, ileum, caecum, and the rectum) from birds in all the groups at the end of the experiment (D16). The tissues were fixed in 10\% formol saline and processed as described by Prophet $e$ al. [28].

\section{Statistical Analysis.}

Data were analyzed using Univariate Analysis of Variance and probabilities of 0.05 or less were considered significant. All data of the faecal oocyst counts $(\mathrm{OPG})$ were normalized using $\log 10(\mathrm{OPG}+25)$. Where appropriate results were summarized as arithmetic means with standard errors of means (S.E.M).

\section{RESULTS}

\section{Faecal Oocyst Counts}

Infection became patent on day 4 in all challenged groups evident by detection of Eimeria oocysts in the faeces of the broiler and indigenous chickens. As expected there were no oocysts in the faeces of uninfected control birds. OPG significantly fluctuated but generally rose as the infection progressed in all groups in both breeds of chickens as depicted in figures $1 \mathrm{a}$ and $\mathrm{b}(\mathrm{P}<0.05)$. The OPG was significantly higher in the broiler than in the indigenous chickens $(\mathrm{P}<0.05)$. In the broilers the OPG of the unimmunized challenged birds was higher than that of the immunized challenged group (Fig. 1a) and the difference was statistically significant $(\mathrm{P}<0.05)$.

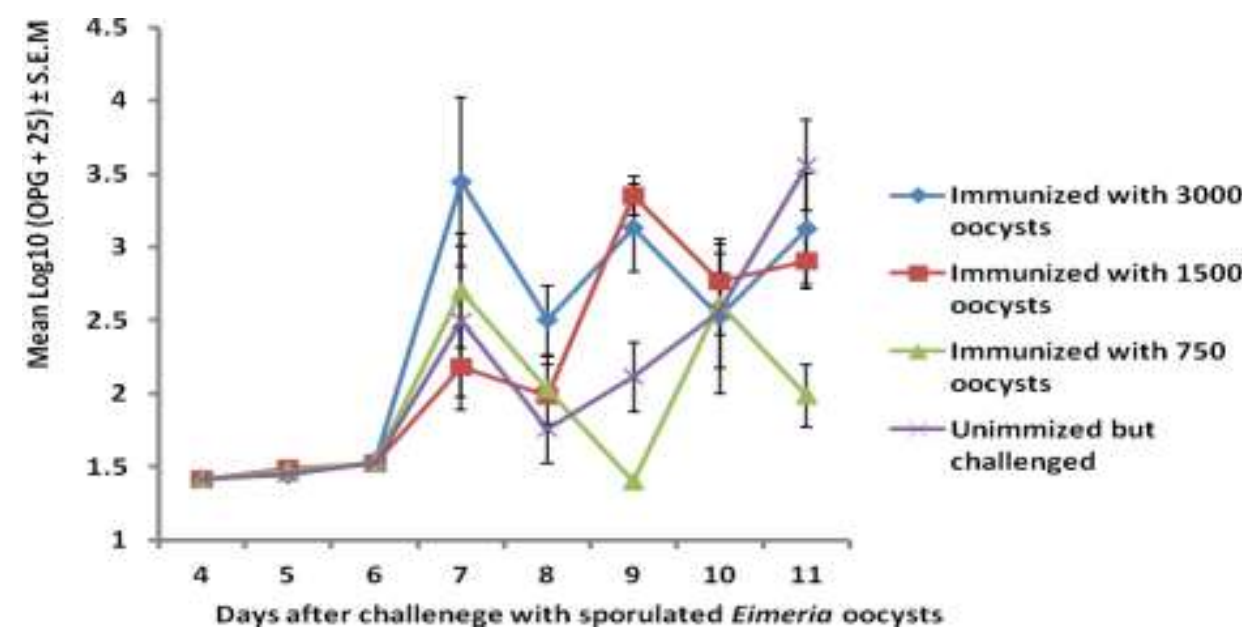

Fig 1a: Mean transformed OPG of broiler chickens immunized with varying dose levels of a caecal isolate of sporulated Eimeria oocysts and challenged with 10,000 sporulated Eimeria oocysts. 


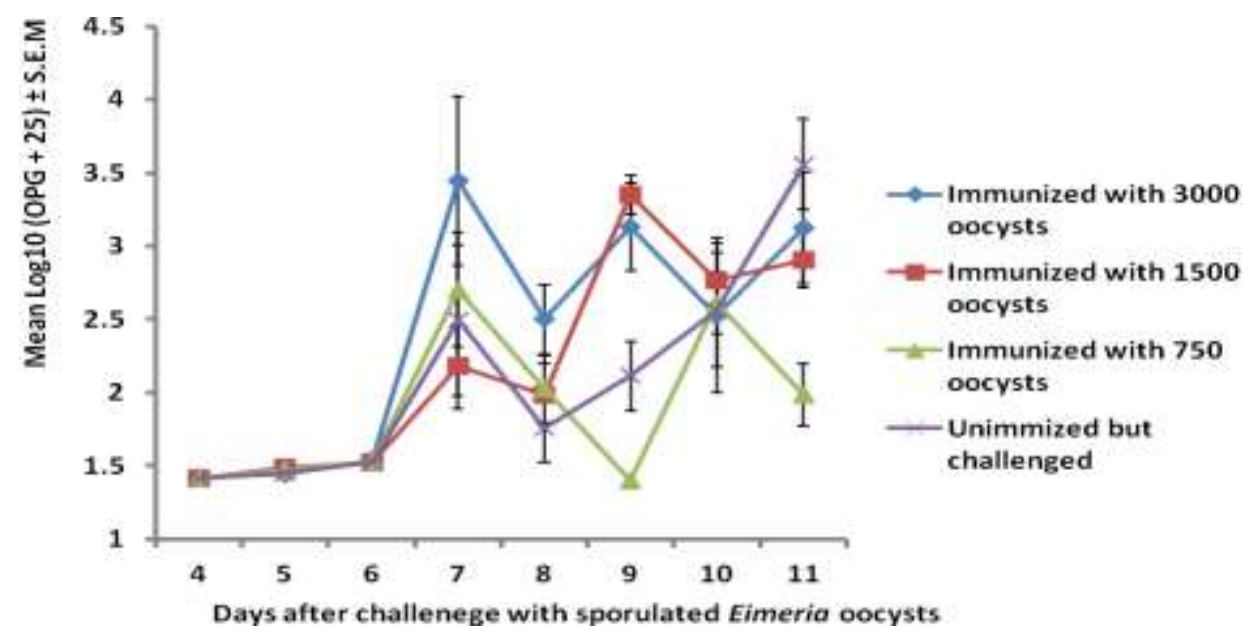

Fig 1b: Mean transformed OPG of indigenous chickens immunized with varying dose levels of a caecal isolate of sporulated Eimeria oocysts and challenged with 10,000 sporulated Eimeria oocysts.

\section{Body Weights}

Figures $2 \mathrm{a}$ and $\mathrm{b}$ represent the mean body weights of the experimental chickens. Body weights varied significantly with time in both breeds of chickens, increasing as the study progressed $(\mathrm{P}<0.001)$. The body weights of broiler chickens varied between groups with the unimmunized-challenged and the uninfected control chickens having significantly higher body weights particularly towards the end of the study on day 20 and day $24(\mathrm{P}<0.05)$. Earlier in the study especially from day 12 to day 16 the unimmunized broiler chickens had significantly higher body weight in comparison to other experimental groups of the breed $(\mathrm{P}<0.05)$. All the chickens had significant weight gain by the end of the study on day 24 (Fig. $2 \mathrm{a}$ and $\mathrm{b}$ ). The mean body weight of the uninfected control of the indigenous chicken was significantly higher than that of the challenged/infected indigenous chickens especially on day $12(\mathrm{P}<0.05)$.

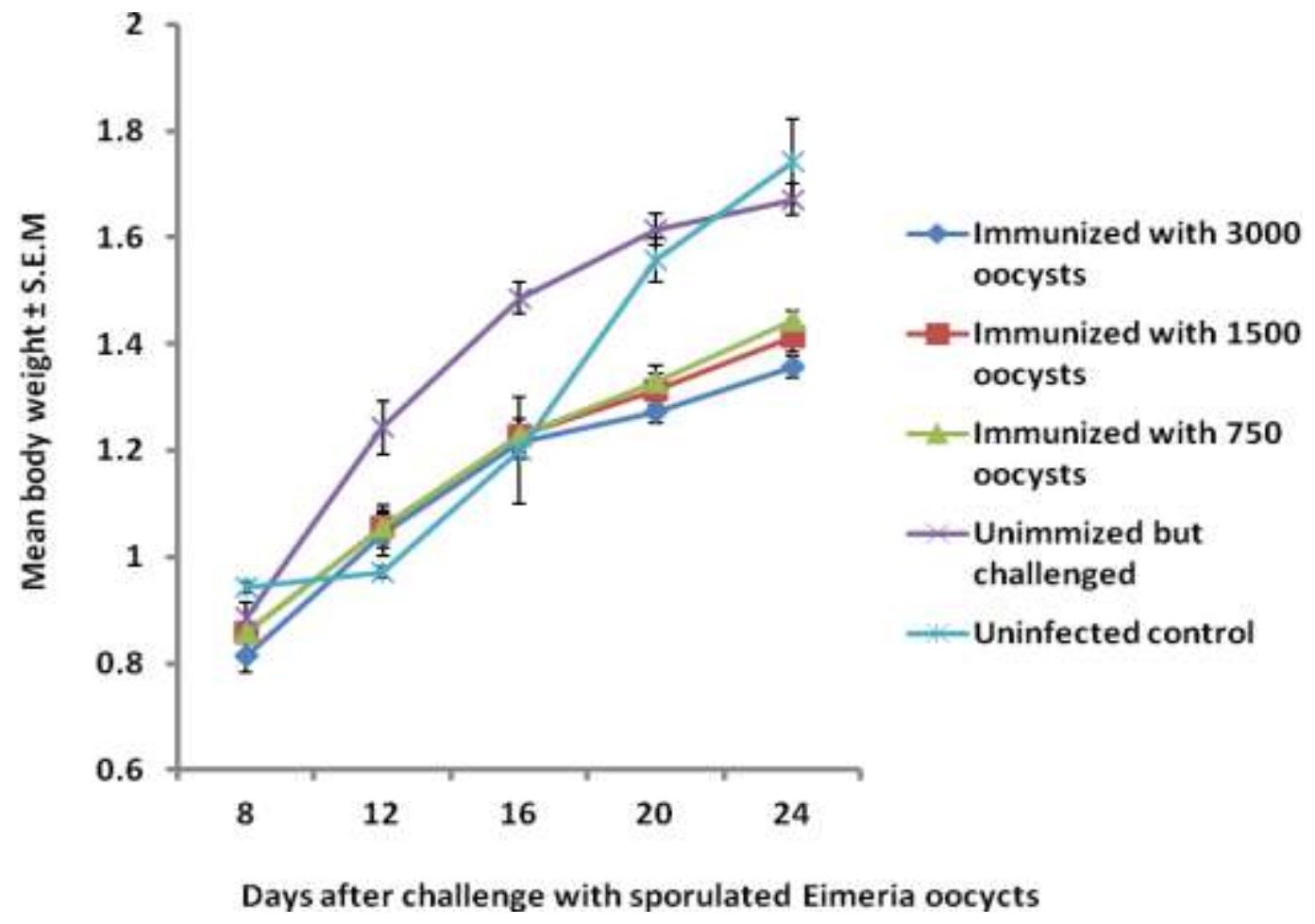

Fig 2a: Mean body weight of broiler chickens immunized with varying dose levels of a caecal isolate of sporulated Eimeria oocysts and challenged with 10,000 sporulated Eimeria oocysts. 


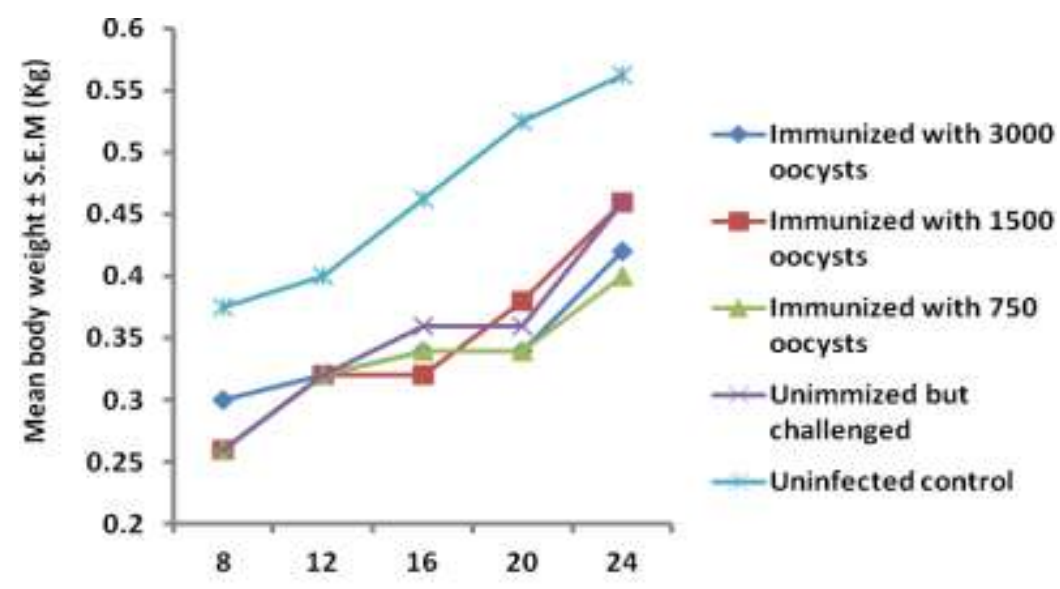

Days after challenge with sporulated Eimeria oocysts

Fig 2b: Mean body weight of indigenous chickens immunized with varying dose levels of a caecal isolate of sporulated Eimeria oocysts and challenged with 10,000 sporulated Eimeria oocysts.

\section{Packed Cell Volume}

\section{Broilers}

Figures1a and $\mathrm{b}$ show the PCV of broiler and indigenous chickens given challenge infection following the immunizing infections. The PCV varied significantly with time in both boiler and local chickens $(\mathrm{P}<0.001)$. The PCV of the infected birds was significantly lower than that of the uninfected control birds of both breeds $(\mathrm{P}<0.05)$. The PCV especially that of the infected birds generally appreciated from their initial low levels to day 24 (Fig 3a and b). The PCV of broilers was significantly $(\mathrm{P}<0.05)$ lower in comparison with that of their local chicken counterparts (Fig $3 \mathrm{a}$ and $\mathrm{b})$.

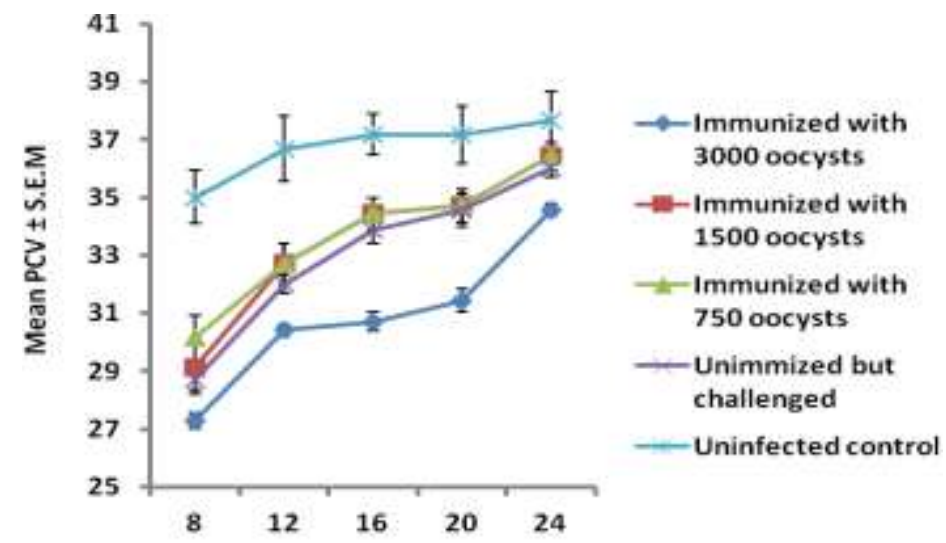

Days after infection with sporulated Eimeria oocysts

Fig 3a: Mean PCVof broiler chickens immunized with varying dose levels of a caecal isolate of sporulated Eimeria oocysts and challenged with 10,000 sporulated Eimeriaoocysts. 


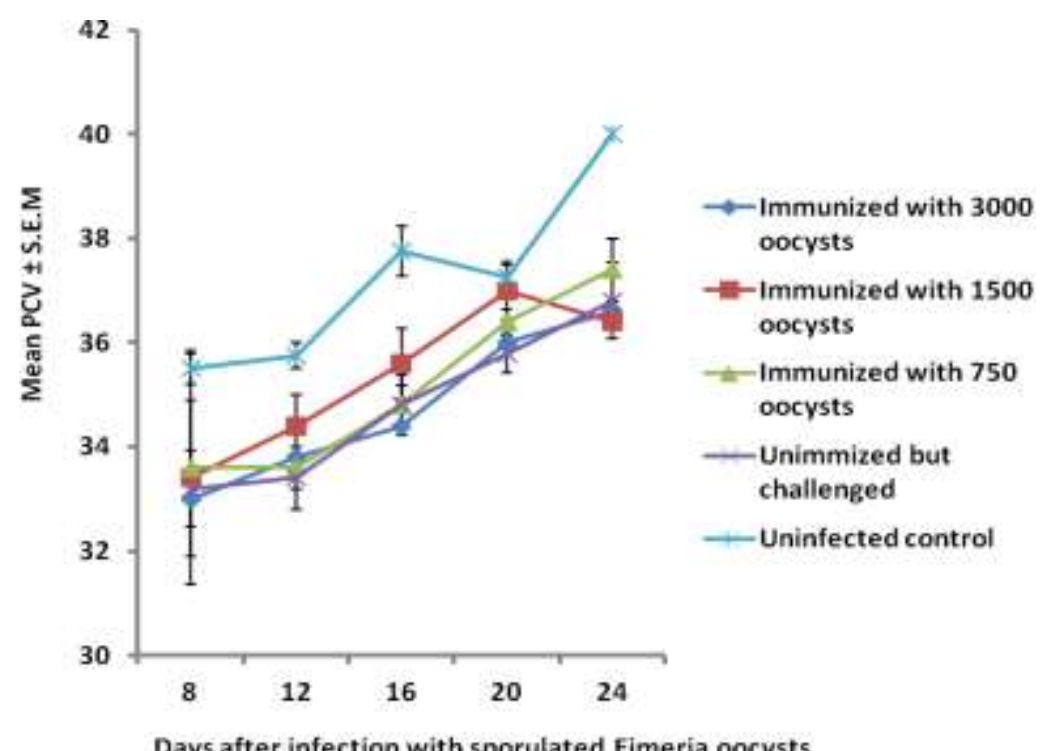

Fig 3b: Mean PCVof indigenous chickens immunized with varying dose levels of a caecal isolate of sporulated Eimeria oocysts and challenged with 10,000 sporulated Eimeria oocysts.

\section{Feed Consumption}

Feed consumption generally increased with time in all experimental groups in both breeds of chickens (Fig 4a and $b$ ) but the consumption rate dropped in the unimmunized-challenged broilers from day 6 to day 16 before resuming the increase on day 18 but remained lower with respect to all other infected and the control groups to day 28 (Fig. $4 \mathrm{a}$ ).

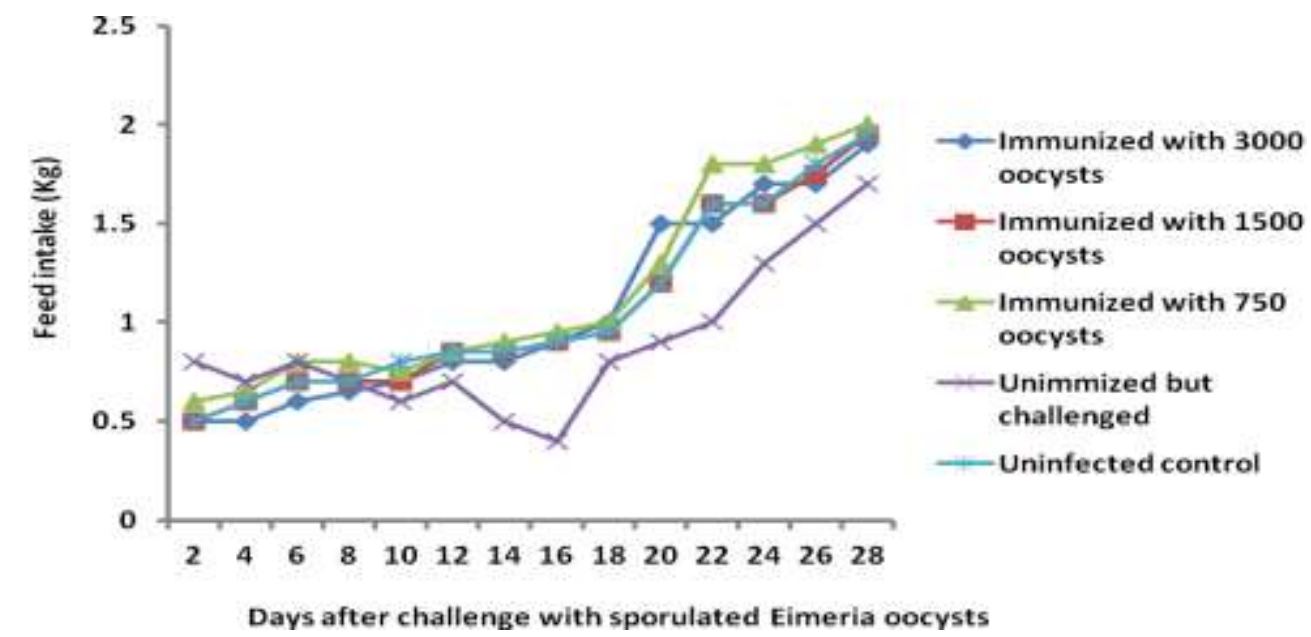

Fig 4a: Feed consumption of broiler chickens immunized with varying dose levels of a caecal isolate of sporulated Eimeria oocysts and challenged with 10,000 sporulated Eimeria oocysts. 


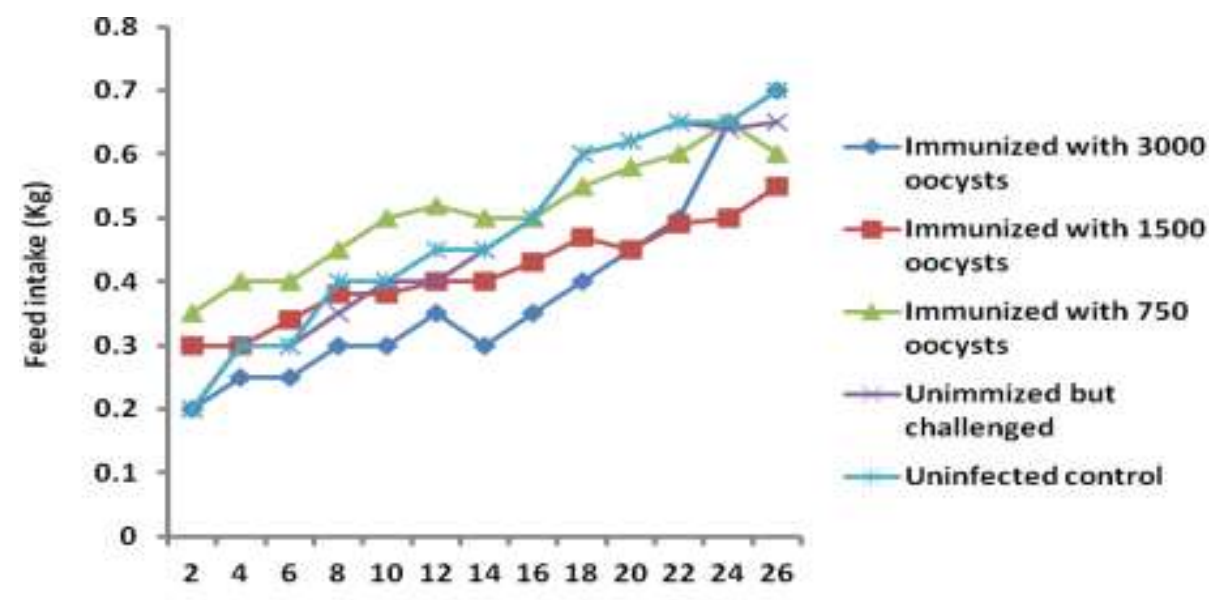

Days after challenge with sporulated Eimeria oocysts

Fig 4b: Feed consumption of indigenous chickens immunized with varying dose levels of a caecal isolate of sporulated Eimeria oocysts and challenged with 10,000 sporulated Eimeria oocysts.

\section{Gross Lesion Examination and Lesion Scores}

Caecal haemorrhages were common in infected chickens. The caecal haemorrhages were more severe in broilers than in the indigenous chickens with lesion scores in the caeca of the unimmunized-challenged chickens ranging from 2 to 4 (with an average score of 2) in the broilers (Fig. 5a and b ) and from 1 to 2 (with an average score of 1) in the indigenous chickens (Fig. 6a and b). Some of the haemorrhages were obvious from the serosal surface of an unimmunized indigenous chicken (Fig. 7). Meanwhile the lesion scores ranged only from 0 to 1 in both the immunizedchallenged broiler and indigenous chickens ( $8 a$ and $b$ ). However, there was no obvious difference in the lesion scores of chickens immunized with different dose levels. As expected, the uninfected control chickens had no coccidial lesions (Fig. 9). Generally, the birds that were immunized and challenged had both fresh haemorrhages and those at advanced stage of healing/resolving with scars/nodules.

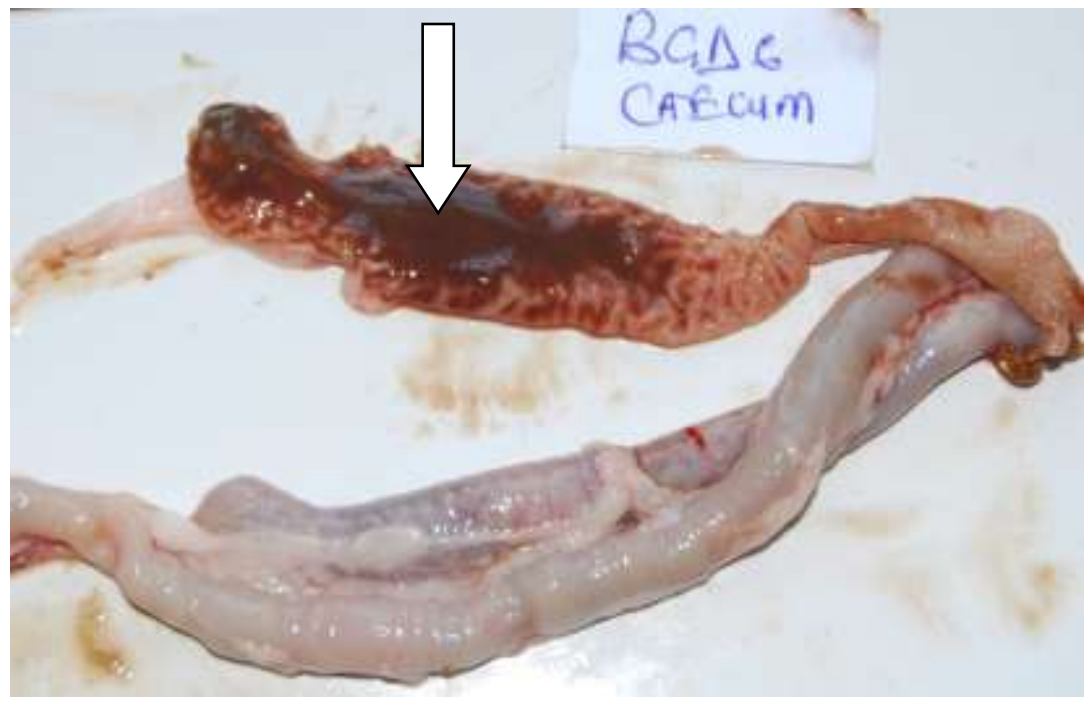

Fig 5a: Caecum of an unimmunized broiler chicken infected with 10,000 sporulted Eimria oocysts with severe haemorrhages (filled with blood) $(+4)$. 


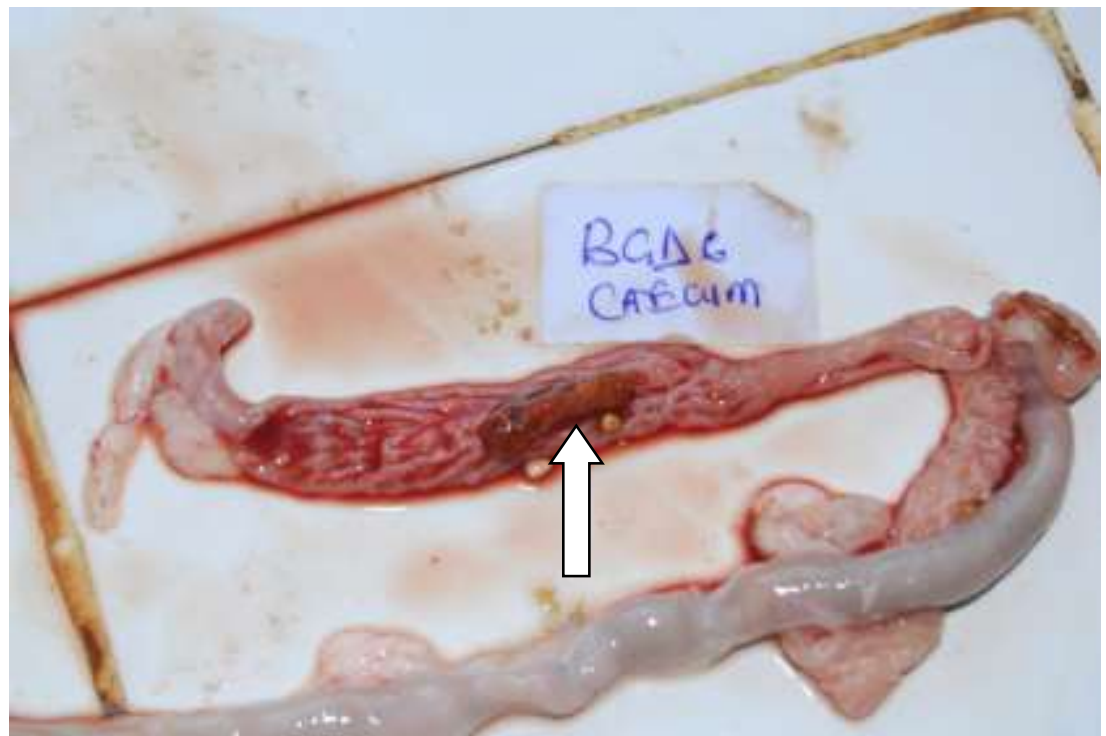

Fig 5b: Caecum of an unimmunized broiler chicken infected with 10,000 sporulated Eimeria oocysts showing bloody contents and caecal cores $(+4)$.

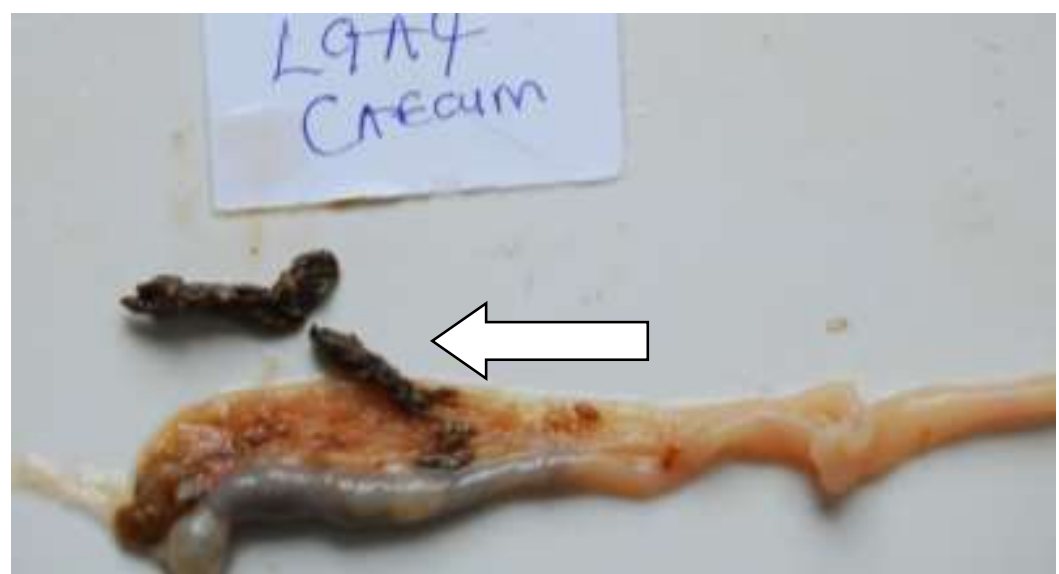

Fig 6a: Caeca of a local chicken immunized with 3000 oocysts and challenged with 10,000 sporulated Eimeria oocysts containing formed bloody faeces $(+1)$

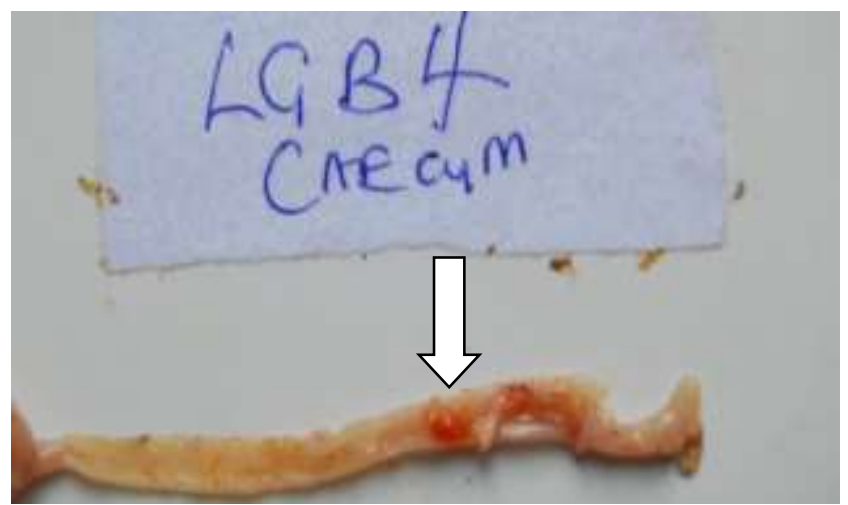

Fig 6b: Caecum of an indigenous chicken immunized with 1500 sporulated Eimeria oocysts and challenged with 10,000 sporulated Eimeria oocysts showing reddish orange contents (0) 


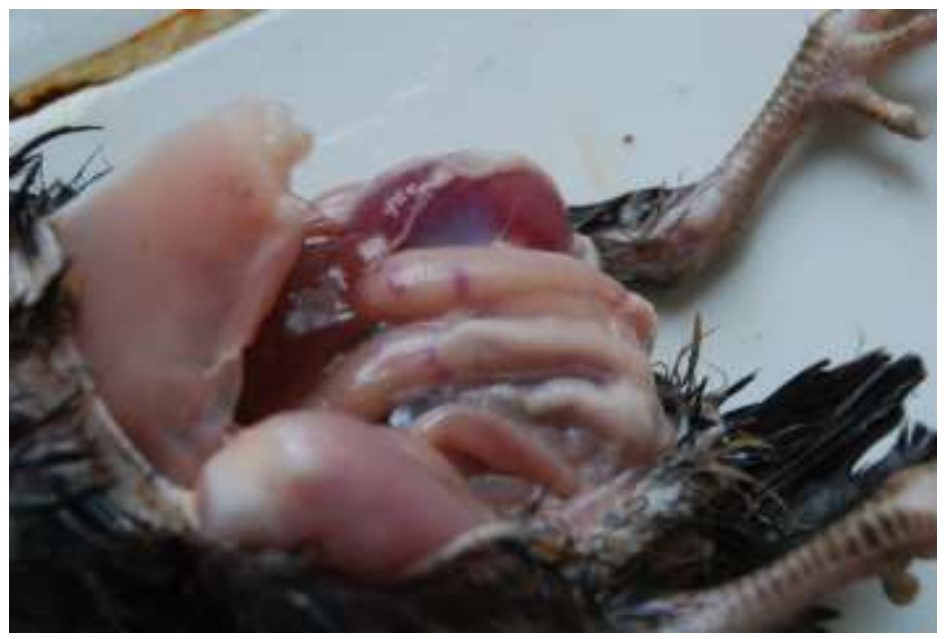

Fig 7: An unimmunized indigenous chicken infected with 10,000 sporulated Eimeria oocysts with haemorrhages obvious from the serosal surface.

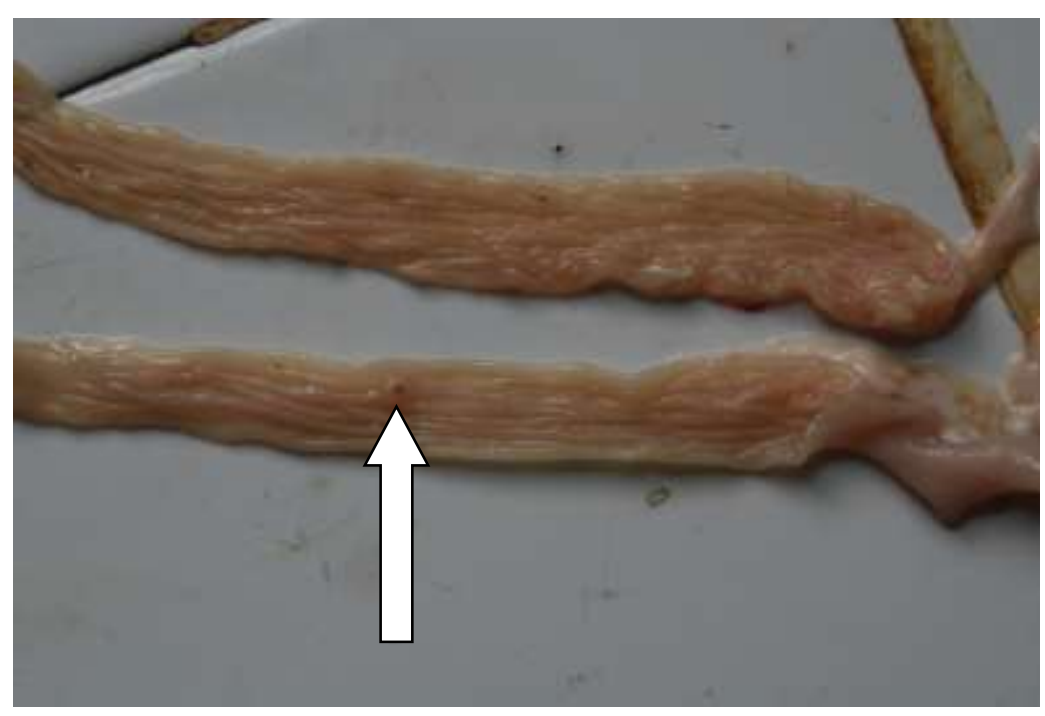

Fig 8a: Caecum of a broiler chicken that was immunized with 3000 oocysts and challenged with 10,000 sporulated Eimeria oocysts demonstratoing a resolving haemorrhagic wound (nodule) $(+1)$.

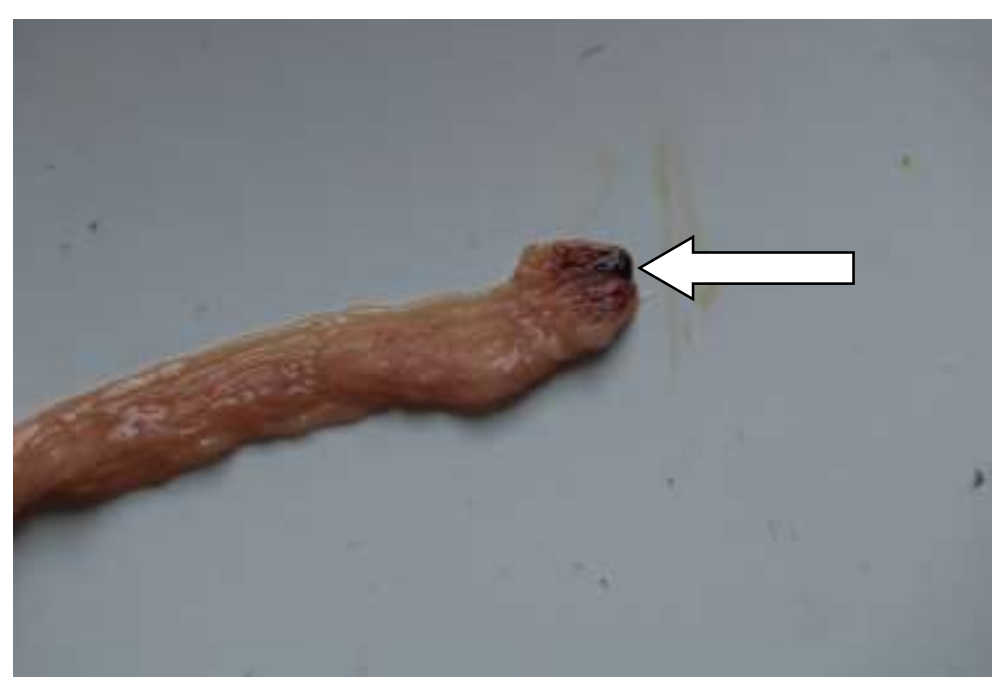

Fig 8b: Caeca of a broiler chicken immunized with 3000 oocysts and challenged with with 10,000 sporulated Eimeria oocysts, showing some haemorrhages which were more severe at the blind end $(+1)$. 


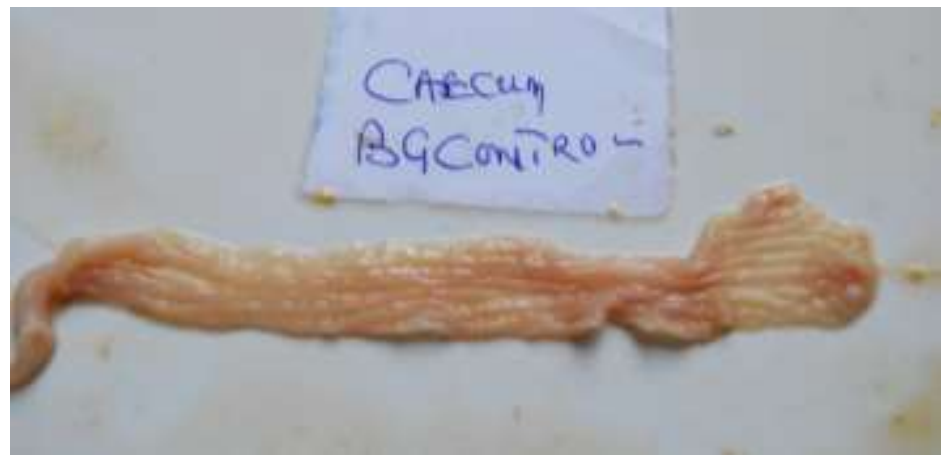

Fig 9: Caecum of uninfected broiler showing the normal mucosa (0).

\section{Microscopic lesions}

While the architecture of the caecal mucosa of the uninfected control chickens (Fig 10) remained intact, the contrary was true for the caecal mucosa of both indigenous and broiler chickens that either received immunizing infections, challenge infections or both immunizing and challenge infections. For example, the caecal mucosa of broiler chickens immunized with 3000 oocysts and challenged with 10,000 oocysts showed cellular infiltration and mild erosions of the (Fig 11). Meanwhile the caecal mucosa of the unimmunized but challenged broiler chickens showed massive cellular infiltration and severe sloughing (Fig 12). Slightly varied intensities of cellular infiltrations and mucosal sloughing were generally common in immunized birds of both breeds (Fig 11, 13, 14, 15).

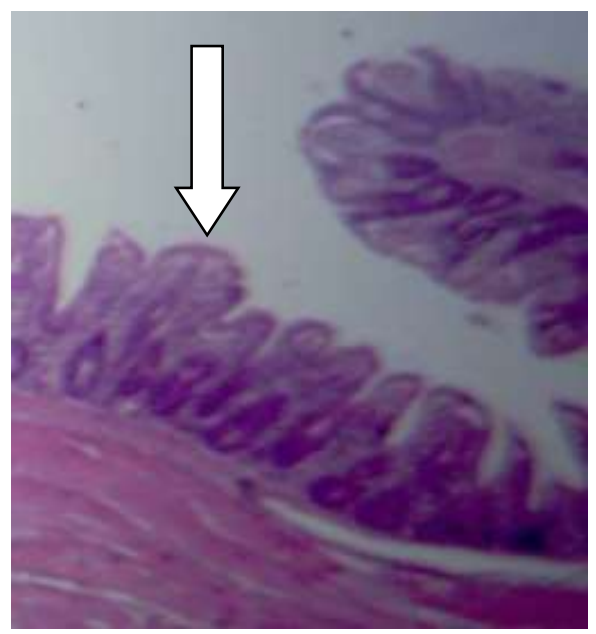

Fig 10: Caecum of an uninfected broiler chicken showing the intact mucosal architecture (H \& E. X 200)

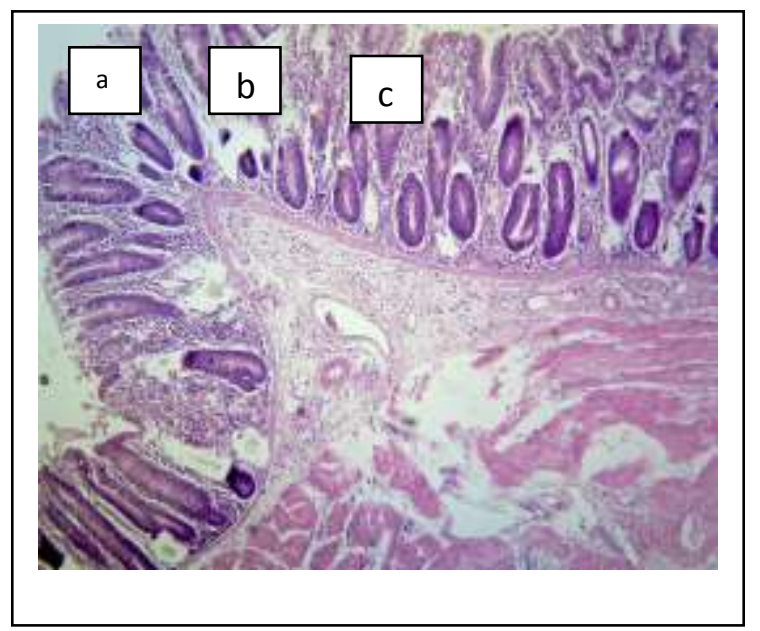

Fig 11: Caecum of a broiler chicken immunized with 3000 Eimeria oocysts and challenged with 10,000 oocysts showing cellular infiltration and mild mucosal erosions. (H \& E. X 100) 


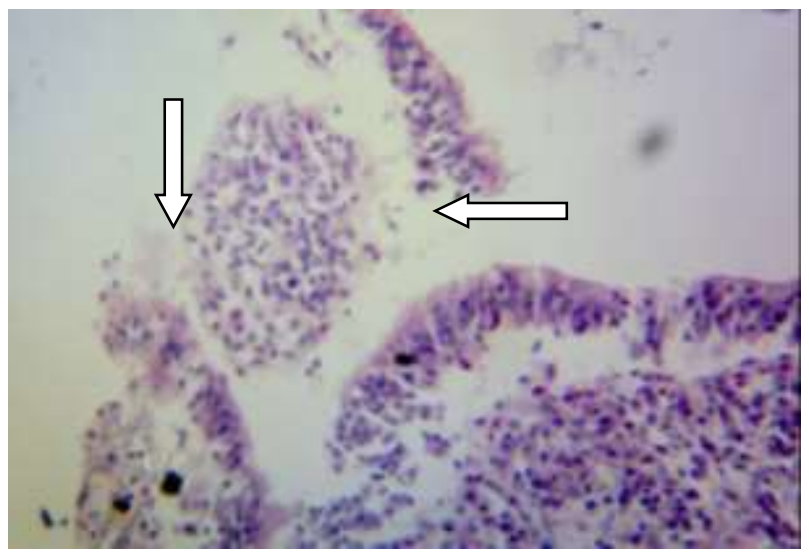

Fig 12. Caecum-D: Caecum of an unimmunized broiler chicken infected with 10,000 Eimeria oocysts showing severe mucosal erosions and massive cellular infiltration. (H \& E. X 400)

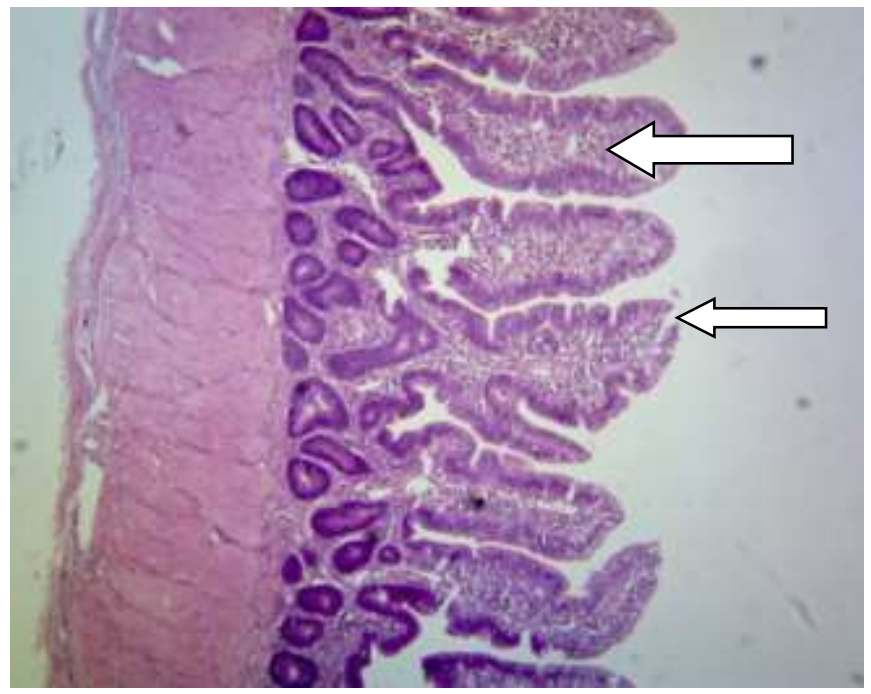

Fig 13: Caecum of an unimmunized indigenous chicken infected with 10.000 Eimeria oocysts showing mild cellular infiltration and mucosal sloughing. (H \& E. X 100)

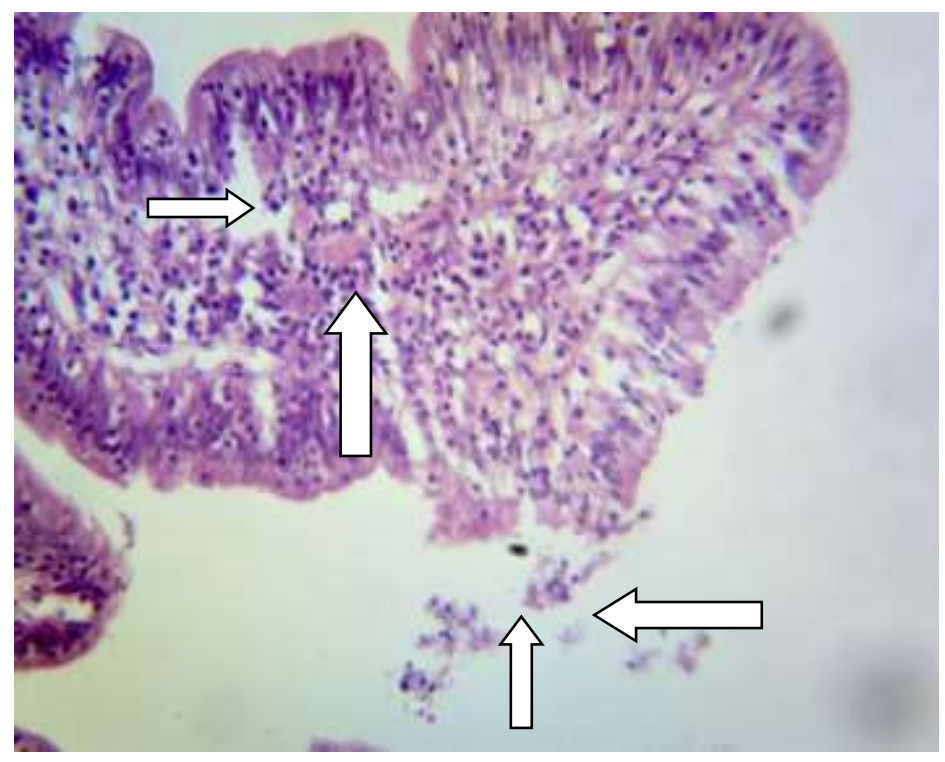

Fig 14: Caecum of an unimmunized indigenous chicken challenged with 10,000 Eimeria oocysts showing cellular infiltration and mild sloughing of the mucosa and oedema. (H \& E. X 400) 


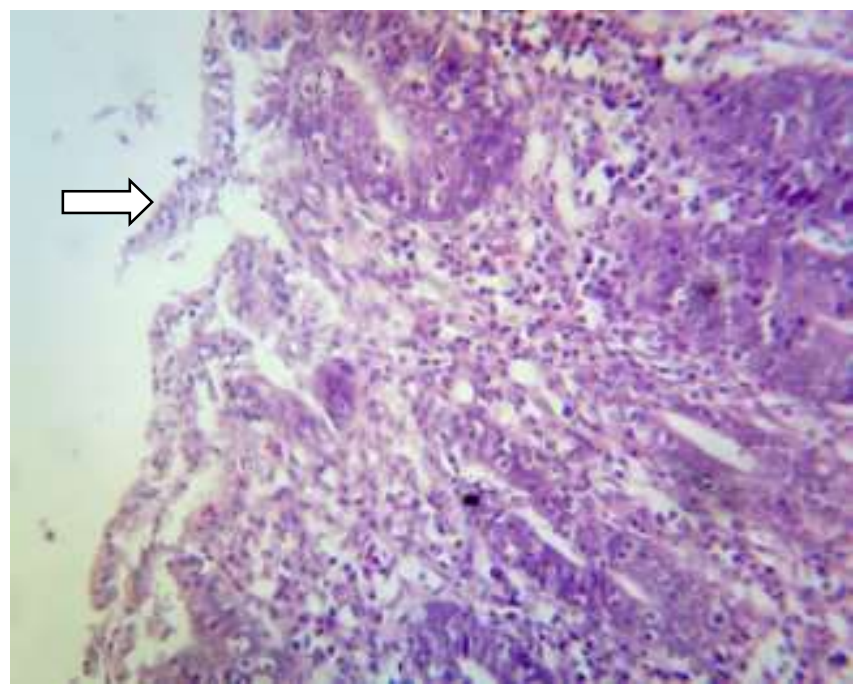

Fig 15: Caecum of an indigenous chicken immunized with 3000 Eimeria oocysts and challenged with 10,000 Eimeria oocysts showing cellular infiltration and mucosal sloughing. (H \& E. X 400)

\section{DISCUSSION}

Patent infections evident by presence of Eimeria oocysts in the faeces depicted establishment in infected birds both in the immunizing and challenge infections. The occurrence of patency on day 4 of infection concords with the findings reported in other studies especially in E. tenella infections in chickens [29, 34]. Immunization therefore did not affect establishment and the prepatent period since the immunized challenged and non-immunized challenged birds of both breeds showed patency on day 4 of the challenge infection. However, clinical signs such as hoodling and bloody diarrhoea were more severe in the unimmunized challenged birds than in the immunized challenged birds in both breeds of birds, an indication of the protective effect of the immunization with the Eimeria isolate.

All immunized chickens showed significant protection for the parameter of gross caecal lesion scores as the immunized challenged birds had mild lesions in contrast to more severe lesions in the unimmunized challenged birds. The excretion of significantly fewer oocysts by immunized challenged broilers in comparison to the unimmunized challenged broilers is also an indication of protection against the infection. The greater potential to cope with the infections in the immunized birds was likely due to the acquired immunity resulting from the immunizing infections. Danforth et al. [30] had reported significant protection in broiler chickens immunized with E. maxima irrespective of the strain of chicken and management system when compared with unimmunized birds.

Since the different immunizing dose levels were all protective and there was no significant difference in protection between them based on lesion scores and some of the other parameters measured, any of the immunizing dose levels tried in the study could therefore be used for immunization against coccidiosis. However, 750 sporulated oocysts would be recommended since it may be difficult to generate large numbers of the oocysts for use and also to limit the possibility of immunization with live vaccine leading to clinical coccidiosis because ingestion of large doses of sporulated Eimeria within a short period can result to clinical coccidiosis [31,32] although it has been reported that high dose levels of the oocysts lead to better protection. Ngongeh [13] has reported that a dose level of 500 Eimeria oocysts was able to produce mild pathogenic effects in 3 week-old broilers and therefore suggested that such low dose levels of sporulated Eimeria oocysts could be used for immunization against subsequent severe Eimeria infections.

The general tendency of PCV rising across all the groups including the control may be partially due to the ageing of the birds as the PCV of older chickens is generally higher than that of young chickens [33]. However, the gradual rise in PCV in the infected birds may be partially due to the subsiding haemorrhages and bloody diarrhoea with resultant reduction of blood as the birds recover. The initial decline in the PCV of the unimmunized challenged birds when compared with that of the immunized challenged birds could be due to lack of protective levels of acquired immunity which was already operational in the immunized challenged birds with resultant more blood loss by the birds. The mild gross lesions (haemorrhages) of 0 - 1 seen in the immunized challenged birds in comparison to the severe gross lesions with lesion scores of up to 2 - 4 in some unimmunized challenged birds further lay credence to the fact that protective immunity was already in play in the immunized birds.

It was also observed that the lesion scores were more severe in the broiler than in the indigenous chickens as it was the case with the OPG which were higher in the broilers compared to the indigenous birds, again a suggestion that the broilers were more susceptible than their indigenous counterparts. The higher PCV of the local chickens further lend credence to the fact that the local breed may be more resistant. Ngongeh et al. (2017) [34] reported that the broiler chickens comparably had lower PCV compared to the local chickens when both were infected with Eimeria oocysts although the local chickens tended to show more obvious clinical signs (bloody faeces and hoodling) than the broilers in 
their study. PCV and gross lesion scores appear to be more consistent findings in Eimeria infections and may likely be better indicators for assessing the susceptibility of chickens to coccidiosis.

All chickens gained weight at the end of the study but the body weight gain was significantly greater in the uninfected control chickens than in the infected ones demonstrating the negative impact of the parasites on weight gain and hence their pathogenicity on the birds. The higher weight gain of the broiler breed across all groups in comparison with their local counterparts was expected since the broilers are a heavy and fast growing breed genetically engineered for meat production. The feed intake of broiler was also higher thereby correlating positively with their heavy weights or suggesting the high feed convertibility.

There were no significant differences in protection based on dose level of the immunizing infections as all chickens that received primary infections responded similarly to the challenge infection. At necropsy, while a lot of haemorrhages and caecal cores with fresh blood were still obvious in the unimmunized birds these were either rare or very mild in their immunized counterparts, which in some cases presented few scars/nodules, an indication of resolving haemorrhages resulting from the earlier immunized infections. One of the broiler chickens from the unimmunized challenge group had a pool of blood and cores in the caeca. As expected there were no lesions the uninfected controls indicating the absence of Eimeria infections and ascertaining that the pathology in the chickens was due to the Eimeria infections.

A solution to the problem of full protection due to lack of some important Eimeria species in the vaccine can be adverted by easily using local isolates for the formulation of vaccines for each locality since the isolate used in this experiment was protective in both breeds of birds in spite of the fact that it was isolated from broiler chickens.

\section{CONCLUSION}

Judged by the parameters measured, immunization had a significant protective role in both breeds of the immunized chickens, however, this was not affected by the dose level of immunizing infection. Broiler chickens suffered more pathology shown by higher lesion scores and lower PCV in comparison with their indigenous counterparts suggesting the greater susceptibility of the broiler breed in comparison with the indigenous breed of chickens. The current findings tend to agree with reports from earlier experimental trials in other parts of the world that different breeds of chickens respond varyingly to Eimeria infections. For example, in Egypt the Fayoumi line of chicken was found to be more resistant to $E$. tenella while the WLDW line was more susceptible to it $[15,30]$. The results of the current study support the possibility of preventing/controlling coccidiosis of birds by immunization.

\section{REFERENCES}

[1] M.M. Hadipour, Olyaie, A., Naderi, M., Azad, F. O. Nekouie, Prevalence of Eimeria species in scavenging native chickens of Shiraz, Iran. African Journal of Microbiology Research. 2011, 5: 3296-3299.

[2] L.R. McDougald, Coccidiosis. In Saif et al. (eds), Diseases of poultry farms in Argentina. Avian Diseases, 2003, 41: 923-929.

[3] R.A. Dalloul, H.S. Lillehoj, Poultry coccidiosis; Recent advancements in control measures and vaccines development. Expert Rev Vaccines, 2006, 5: 143-163.

[4] H.S. Lillehoj, Kim, C.H., Keeler Jr., C.L., Zhang, S, Immnogenomic approaches to study host immunity to enteric pathogens. Poutry Science. 2007, 86: 1491-1500.

[5] P.A. Sharman, Smith, N.C., Wallach M.G., M. Katrib, Chasing the golden egg: vaccination against poultry coccidiosis. Parasite Immunol. 2010, 32(8): 590-8. doi;10.1111/j.1365-3024.2010.01209.x.

[6] R.B. Williams, R.B. \& Catchpole, J. (2000). A new protocol for a challenge test to assess the efficacy of live anticoccidial vaccines for chickens. Vaccine, 18, 1178 -1185

[7] K.R. Price, Use of live vaccines for coccidiosis control in replacement layer pullets.J Appl Poult Res, 2012,21 (3): 679-692. doi: 10.3382/japr.2011-00486

[8] M.E. Rose, 1973a. Immunity. In: 'The coccidia' (D.M. Hammond and P.L. Long. eds.), pp. 293-341. Uni. Park Press, Baltimore, Maryland.

[9] M.E. Rose, Immune responses of chicken to coccidian and coccidiosis. In: Long, P.I., Boorman, K.N., Freeman, B.M. (eds) Avian Coccidiosis 1978, pp.297-338. British Poultry Science Ltd., Edinburg, Uk.

[10] R.B. Williams, Bushell, A.C., R'ep'erant, J.-M., Doy, T.G., Morgan, J.H., Shirley, M.W., Yvor'e, P., Carr, M.M. \& Fr'emont, Y, A survey of Eimeria species in commercially-reared chickens in France during 1994. Avian Pathology, 1996, 25: 113-130.

[11] H.D. Danforth (1998). Use of live oocyst vaccines in the control of avian coccidiosis: experimental studies and field trials. Int. J. Parasitol. 28: 1099-109.

[12] R. B. Williams, Anticoccidial vaccines for broiler chickens: Pathways to success. Avian Pathology, 2002, 31(4): 317-353, DOI: 10.1080/03079450220148988.

[13] L.A. Ngongeh, Prevalence, characterization and pathogenicity of Eimeria species in chickens reared in Nsukka area of Enugu State, Nigeria. A Fellowship Thesis, College of Veterinary Surgeons Nigeria, 2015. 
[14] H.S. Lillehoj, Influence of inoculation dose, inoculation schedule, chicken age and host genetics on disease susceptibility and development of resistance to Eimeria tenella infection. Avian Dis. 1988, 32: 437-444.

[15] M.H. Pinard-Van Der Laan, Monvoisin J.L., Pery P., Hamet N., M. Thomas, Comparison of outbred lines of chickens for resistance to experimental infection with coccidiosis (Eimeria tenella). Poult Sci. 1998, 77(2): $185-91$.

[16] J.J. Zhu, H.S. Lillehoj, P.C. Allen et al., Mapping quantitative trait loci associated with resistance to coccidiosis and growth. Poultry Science, 2003, 82: 9-16.

[17] J.C. Rodriquez J.C., Segura J.C, Alzina A., M.A. Gutierrez, Factors affecting mortality of cross breed and exotic chickens kept under backyard systems Yucatan, Mexico. Trop. Anim. Health. Prod. 1997, 29: 151-157.

[18] A.J., Trees, Parasitic diseases in F.T.W. Jordan and M. Pattison. Poultry Diseases. Fourth edition. W.B. Saunders Company, Ltd., 1999, 34: 261-281.

[19] M.W. Shirley, Millard, B.J. Studies on the immunogenicity of seven attenuated lines of Eimeria given as a mixture to chickens. Avian Pathology, 1986, 15: 629-638.

[20] M.W. Shirley, Control of coccidiosis with vaccines. In Proceedings of the Second Asian/Pacific Poultry Health Conference, 1988a, pp. 129-157. Surfers' Paradise, Australia.

[21] R.B. Williams, Epidemiological aspects of the use of live anticoccidial vaccines for chickens. International Journal for Parasitology, 1998a, 28: 1089-1098.

[22] J.W. Ward, J.R. Elsea, Animal case and use in drug fate and metabolism. In: Edward, RJ, Jean LH Editors. Methods and techniques. $1^{\text {st }}$ Edn. New York. Publisher, Markel, 1997.

[23] J.V. Dacie, S.M. Lewis. Practical haematology, eighth ed. Churchill Livingstone, 609, 1995.

[24] MAFF, Manual of Veterinary Laboratory Diagnostic Techniques, Bulletin Number 18, Ministry of Agriculture Fisheries and Food (MAFF), HMSO, London, UK, 1977.

[25] D.V. Zander, Diseases of poultry, 7th ed..Iowa State University Press/ Ames, lowa, U.S.A., 1978, pp. 3-48. $6 / 6 / 2012$.

[26] D.P. Conway, M.E. McKenzie, Examination of lesions and lesion scoring. In: Poultry coccidiosis - diagnostic and testing procedures, $2^{\text {nd }}$ ed. Pfizer Inc., New York. 1991, pp17 -36.

[27] D. P. Conway, K. Sasai, S. M. Gaafar, and C. D. Smothers, Effects of different levels of oocyst inocula of Eimeria acervulina, E. tenella, and E. maxima on plasma constituents, packed cell volume, lesion scores, and performance in chickens. Avian Diseases, 1993, 37: 118-123.

[28] E.B. Prophet, Mills, B., Arrington, J. B., K.W. Hincliff, Laboratory methods in histotechnology. Washington: Armed Forces Institute of Pathology, 1992.

[29] D.L. Zulpo, J. Peretti, L.M. Ono, E. Longhi and M.R. Oliveira et al., Pathogenicity and histopathological observations of commercial broiler chicks experimentally infected with isolates of Eimeria tenella, E. acervulina and E. maxima. Semina Ciencias Agrarias Londrina, 2007, 28: 97-104.

[30] H.D. Danforth, K. Watkins, A. Martin, M. Dekich, Evaluation of the immunizing efficacy of Eimeria maxima oocyst immunization with different strains of day-old broiler and roaster chickens. Avian Dis., 1997, 41(4): 792-801.

[31] A. A. Tarek, Bassant A. El-Sayed, Laila H. El-Saye, Development of immunization trials against Eimeria spp. Trials in Vaccinology. 2016, 5: 38-47.

[32] K. Price, J.R. Barta, Immunological control of coccidiosis, Open Journal Systems, 2010 4(1).

[33] V. McDonald and W.M. Shirley, Past and future: vaccination against Eimeria. Parasitology, 2009, 136: 1477-1489.

[34] Ngongeh, L.A., Onyeabor, A., Nzenwata, E., Gurama, S.K. (2017). Comparative Response of the Nigerian Indigenous and Broiler Chickens to a Field Caecal Isolate of Eimeria Oocysts. Journal of Pathogens. https://doi.org/10.1155/2017/2674078. 